\title{
O contexto da educação especial na perspectiva da educação inclusiva:
}

\author{
as vozes dos professores e dos familiares na rede municipal de ensino de \\ Joinville (SC).
}

\author{
Carin Schultze Fettback ${ }^{1}$ \\ Nelma Baldin²
}

RESUMO: Este artigo tem por objetivo analisar a aplicabilidade das diretrizes expressas nos documentos que orientam a Política Nacional de Educação Especial na Perspectiva da Educação Inclusiva, buscando compreender o relacionamento entre família, escola e atendimento educacional especializado. Objetivos específicos: avaliar o entendimento que têm as famílias e os professores quanto ao AEE da pessoa com deficiência; compreender os dizeres das famílias e dos professores, o processo de inclusão da criança e do adolescente no ensino regular; reconhecer a importância, para a família, da representação das relações no referente à família-escola e família-AEE. Participaram de estudo 15 famílias, três professoras do AEE, 46 professores do ensino regular e cinco auxiliares monitores. Utilizando fichas de observação, diário de campo, caderno de notas, entrevistas semiestruturadas, aplicação de questionário e observações nas escolas, os descritores do estudo: educação especial, família e representação social, a abordagem da pesquisa qualitativa etnográfica e também o estudo com aplicação de técnicas quantitativas. Resultados apontam divergências quanto às opiniões no que se refere ao relacionamento entre os pais e professores nas escolas, uma vez que a inclusão dos estudantes com deficiência e transtorno global do desenvolvimento continua sob responsabilidade da educação especial. Pais e professores demonstram desconhecer o AEE.

PALAVRAS CHAVE: Educação Especial; Família; Representação Social.

ABSTRACT: This article has the objective of analyzing the applicability of the guidelines contained in the documents that establish the National Policy of Special Education in the Perspective of the Inclusive Education (2008) with focus in understanding the relationship between family, school, and the special needs educational service. The research in which this article is based had as specific objectives: to assess the understanding that families and teachers have about services to special needs students; to understand the sayings of family members and teachers, the inclusion process of children and adolescent in the regular school; to recognize the importance

\footnotetext{
${ }^{1}$ Mestre em Educação. Universidade da Região de Joinville - UNIVILLE. fettback.carin@gmail.com

²Doutora em Educação. Universidade da Região de Joinville - UNIVILLE. nelma@univille.br
} 
given by family to the representation of relations regarding family-school and familyspecial needs educational service. Fifteen families took part in this study (an aunt, a brother, a father, and twelve mothers), besides three special needs educational service teachers, forty-six elementary school teachers, and five special needs student assistants. Using observation charts, field diaries, notes, semi-structured interviews with parents, as well as survey with teachers and observation of the school routine, we came to the description markers: special needs education, family, and social representation, that highlight the qualitative ethnographic approach of this study, but quantitative techniques were also used. The results point out to controversies in opinions about the relationship between parents and teachers at school level, since the inclusion of children and adolescents with deficit and global developmental disruption continues to be the responsibility of the special education area. There are still parents and teachers who showed that they don't know about the existence of special needs educational services.

KEYWORDS: Special Education; Family; Social Representation.

\section{INTRODUÇÃO}

Neste artigo, visa-se apresentar uma parcela dos principais resultados de uma pesquisa que tratou da relação família, escola e Atendimento Educacional Especializado (AEE), realizada no Município de Joinville (SC).

O pano de fundo para o início da pesquisa foi a busca da história da Educação Especial no Brasil, entendendo-se que a segregação, o abandono, o preconceito, a concepção da deficiência como doença, o fatalismo, a maldição, o pecado pessoal ou da família ou a visão de incapacidade fizeram parte da história da civilização e da vida das pessoas com deficiência até bem pouco tempo.

Segundo afirma Mazzota (2011), a despeito de figurar na política educacional brasileira desde o final da década de cinquenta do século passado até os dias atuais, a Educação Especial tem sido, com grande frequência, interpretada como um apêndice indesejável. O sentido a ela atribuído é, ainda hoje, muitas vezes, o de assistência às pessoas com deficiência, e não o de educação de crianças e adolescentes que apresentam necessidades específicas.

Nas décadas de 1960 e 1970, a sociedade foi marcada pelos valores vivenciais, culturais, sociais, econômicos e políticos que interferiram diretamente no atendimento 
das pessoas com deficiência. Para se tornarem aptas aos padrões aceitos na vida social, as pessoas com deficiência deviam ser modificadas, habilitadas, reabilitadas e educadas.

Nas décadas de 1980 e 1990, a concepção de uma sociedade inclusiva passou a ganhar mais espaço, sendo capaz de modificar-se para atender as pessoas com deficiência nas suas necessidades específicas. Segundo Mantoan e Santos (2010), inclusão trata-se de uma inovação cujo sentido tem sido muito polemizado e por vezes distorcido pelos mais diferentes segmentos educacionais e sociais.

Os diferentes contextos históricos, as transformações nas diversas esferas da vida social e os novos comportamentos vêm possibilitando uma nova percepção acerca das pessoas com deficiência. Em vista disso, a Política Nacional de Educação Especial na Perspectiva da Educação Inclusiva (BRASIL, 2008) é constituída e, devido ao seu impacto educacional, exerce influência significativa nos modos de aprender e ensinar na escola, orientando e subsidiando os Sistemas de Ensino em relação à Educação Especial.

O principal objetivo da referida política é o de assegurar a inclusão escolar de crianças e adolescentes com deficiência, transtorno global do desenvolvimento e altas habilidades/superdotação. Para tanto, deu-se importância relevante aos seguintes quesitos: 1) Atendimento Educacional Especializado - $A E E$, que identifica, elabora e organiza recursos pedagógicos e de acessibilidade que possam eliminar as barreiras para a plena participação dos alunos, considerando as suas necessidades específicas. Esse atendimento complementa e/ou suplementa a formação dos alunos com vistas à autonomia e independência na escola e fora dela; 2) Participação da família e da comunidade escolar para serem protagonistas de ações educacionais que venham a reconhecer e valorizar as diferenças presentes no cotidiano escolar, construindo condições efetivas de participação e aprendizagem para todos (BRASIL, 2008).

Diante da literatura disponível, foi possível avançar mais na pesquisa, buscando compreender como se processa a inclusão das crianças e dos adolescentes com necessidades específicas no contexto educacional e qual a implicação da participação da família nesta inserção. Entende-se que a família constitui-se em uma 
das mais importantes instâncias coletivas que pode corroborar para a inclusão escolar mediante o desenvolvimento de um processo coletivo junto à escola, no qual envolve, nesta ação, tomada de decisões, comprometimento e corresponsabilidade.

A participação efetiva da família no processo de aprendizagem é fundamental para o desenvolvimento das crianças e dos adolescentes frente às suas necessidades. Porém, as pesquisadoras concordam com Paulon (2007) ao compreender que o nascimento de um filho com deficiência traz uma série de impasses às relações familiares, seguidos de sentimentos de frustração, culpa, negação do problema, entre tantos outros. Compreendem, ainda, que esses problemas tenderão a se avolumar caso a família não receba a ajuda necessária para reconhecer seu filho como um sujeito que apresenta diversas possibilidades.

A posição da família da criança e do adolescente com necessidades específicas é apontada como um obstáculo no processo de inclusão educacional quando dificulta a inclusão escolar por não reconhecer as possibilidades da criança (GODOI, 2006). A família é um coletivo que necessita, para seu pleno desenvolvimento, garantir a participação de todos no compartilhar sentimentos, na análise dos problemas, no processo de tomada de decisões e responsabilidades.

Considerando a importância das informações coletadas e dos apontamentos realizados no decorrer da pesquisa, pensou-se ser conveniente ouvir as vozes dos familiares sobre as necessidades e expectativas com relação à vida escolar dos seus filhos com deficiência, buscando compreender, nesse processo, qual a representação, para a família, da interação família/escola. Também buscou-se conhecer a percepção dos professores sobre esse processo de interação.

Todos esses movimentos possibilitaram oportunizar a ampliação de reflexões sobre a realidade existente no que se refere à inclusão de crianças e adolescentes com necessidades específicas. Como afirmam Nogueira (1998), Nunes e Vilarinho (2001) e Chug (1998), os estudos sobre a representação da família em relação à inclusão escolar auxiliam na reflexão sobre e na realidade e também sobre como lidar com a família, permitindo a "reconstrução" das representações dessas relações. 
Nesse encaminhamento, a teoria das Representações Sociais ofereceu-nos subsídios para o entendimento e a discussão acerca das novas configurações familiares que adentram no contexto social e escolar onde se encontram inseridas (MOSCOVICl, 2003). A teoria de Moscovici tornou-se pertinente ao estudo por oportunizar que as imagens, crenças, representações sociais e o conceito de família fossem passíveis de discussão e reflexão dentro do binômio família-escola.

É na família que a criança encontra os primeiros "outros" e, por meio deles, aprende os modos humanos de existir. Nesse contexto, o mundo da criança adquire significado e ela começa a constituir-se como sujeito (SZYMANSKI, 2010). A participação da família e da comunidade junto à escola traz, para o ambiente escolar, informações, críticas, sugestões, solicitações, desvela necessidades e sinaliza rumos (ARANHA, 2004). Entretanto, sabe-se que a família tem se encontrado, historicamente, numa posição de dependência de profissionais em diferentes áreas do conhecimento, em especial no sentido de receber orientações de como proceder em relação às necessidades específicas de seus filhos (BRASIL, 2004).

Assim, neste estudo, corroboramos com Santos e Mantoan (2010) na compreensão de que a escola ainda necessita passar por transformações importantes, sair do espaço onde a inclusão escolar ocorre de forma instrumental e centrada basicamente em adaptações, e tentar superar a cultura seletiva, classificadora, normalizadora e excludente da educação escolarizada. Isto é, passar para uma escola realmente inclusiva.

Esse pensamento é compartilhado por Bock (2012), o qual indica que a construção de uma escola inclusiva é uma tarefa social que envolve o corpo interno da escola articulado com órgãos e instituições externas, dentre esses, em especial, a família. Trata-se, portanto, de realizar um esforço para se pensar em conjunto.

Sabe-se que a escola inclusiva não irá acabar de forma milagrosa com os conflitos entre as expectativas escolares e as prováveis impossibilidades em atendêlas. A união entre escola e família poderá possibilitar a construção de consensos e garantir às pessoas com deficiência espaço e experiências que Goffmann (1988) 
considera como "metamorfoses", ou seja, oportunizar a autoconstrução para pessoas dignas e criativas.

Sob esse viés, é essencial que se invista na orientação e no apoio à família para que esta possa cumprir com seu papel educativo junto a seus filhos, acompanhando e participando da resolução dos problemas da escola relacionados ao desenvolvimento e aprendizagem dos estudantes e, em particular, do seu filho, ajudando-o a superar as dificuldades (PAULA, 2007).

Uma das funções da Educação Especial é estreitar a relação com a família, alcançando e compartilhando um trabalho interdisciplinar e colaborativo na unidade escolar. Em vista dessa função, uma das inovações trazidas pela Política Nacional de Educação Especial na Perspectiva Inclusiva é o Atendimento Educacional Especializado - AEE, que contribui para minimizar ou eliminar as barreiras para a plena participação das crianças e dos adolescentes, considerando suas necessidades específicas, por meio de ações e atividades realizadas nas salas de recursos multifuncionais localizadas nas escolas de educação básica (BRASIL, 2008). Dessa forma, a escola pode auxiliar na aproximação das crianças e adolescentes do AEE ao dia a dia escolar e com todos que atuam no ensino regular, aproximando-os dos ambientes de formação comum a todos.

Ropolli (2010, p. 18) contribui com as discussões sobre esta inclusão, afirmando que

para os pais, quando o Atendimento Educacional Especializado - AEE ocorre nessas instituições/circunstâncias, propicia-lhes viver uma experiência inclusiva de desenvolvimento e de escolarização de seus filhos, sem ter de recorrer a atendimentos exteriores à escola.

Além desse benefício, a parceria entre família e escola traz aspectos como: a família torna-se mais informada em relação aos seus direitos, responsabilidades e recursos, e também mais esclarecida sobre a deficiência apresentada pelas crianças e adolescentes. Como indica Perez (2007), deve-se "tratar a família como parceira e não como adversária". Outro ponto importante é que, com a proximidade da família, os profissionais adquirem maior conhecimento sobre suas características, necessidades e potencialidades. 
Por outro lado, foi importante para o desenvolvimento da pesquisa o ato de conhecer as representações que a família tem em relação à escola onde suas crianças e adolescentes estudam. Esse conhecimento é determinante e poderá influenciar no cotidiano, nas atitudes, nas tomadas de decisão, enfim, nas práticas, justamente porque essas mesmas práticas são dinâmicas e estão relacionadas às mudanças sociais.

Considerando a contextualização acima exposta, enfatiza-se, aqui, que o objetivo geral da pesquisa é analisar a aplicabilidade das diretrizes expressas nos documentos que orientam a Política Nacional de Educação Especial na Perspectiva da Educação Inclusiva (BRASIL, 2008), visando compreender o relacionamento entre família, escola e Atendimento Educacional Especializado. Para melhor alcançar essa expectativa, os objetivos específicos centram-se em: avaliar o entendimento que têm as famílias e os professores quanto ao atendimento educacional especializado - AEE da pessoa com deficiência; compreender os dizeres das famílias e dos professores sobre o processo de inclusão da criança e do adolescente com deficiência e transtorno global do desenvolvimento no ensino regular; reconhecer a importância, para a família, da representação das relações sociais no referente à família-escola e família-atendimento educacional especializado.

\section{MÉTODO}

A abordagem da pesquisa é qualitativa. Segundo Minayo, Deslandes e Gomes (2009), a pesquisa qualitativa responde a questões muito particulares, pois trabalha com o universo dos significados, dos motivos, das aspirações, das crenças, dos valores e das atitudes. Está muito próxima da pesquisa etnográfica que, conforme André (2009), caracteriza-se, fundamentalmente, por um contato direto do pesquisador com a situação pesquisada e permite reconstruir os processos e as relações que configuram a experiência escolar diária. André (2009) indica, ainda, que por meio da observação participante e de entrevistas intensivas é possível documentar o não documentado, desvelar o dia a dia da prática escolar, descrever as representações dos agentes sociais, reconstruir suas linguagens e suas formas de comunicação. Nessa direção, a 
pesquisa aqui relatada centrou-se no contato direto das pesquisadoras com a população pesquisada.

A pesquisa foi realizada em um contexto no qual a inclusão escolar, entendida como processo, permeia as mais variadas situações da sociedade, dentre elas a escola com as suas salas de aula e professores do ensino regular, salas de recursos multifuncionais com suas professoras do atendimento educacional especializado, e a família, com as figuras paterna, materna e/ou demais membros responsáveis.

O trabalho de campo da pesquisa, acontecido entre março e julho de 2012, possibilitou acompanhar e conhecer a dinâmica das unidades escolares. Por meio das vozes (entrevistas) dos familiares de crianças e adolescentes com Deficiência e Transtorno Global do Desenvolvimento, (aplicação de questionário) dos professores do ensino regular, do atendimento educacional especializado - AEE e dos auxiliares de educadores monitores de três escolas municipais da cidade de Joinville - SC, identificadas, neste artigo, como escola $A, K$ e $V$, obteve-se as informações que possibilitaram que se atingissem os objetivos previstos. Participou da pesquisa um total de oitenta e quatro (84) pessoas.

As crianças e os adolescentes com deficiência e transtorno global do desenvolvimento foram observados in loco, na escola, e os registros foram firmados em uma ficha específica, o que possibilitou uma revisão, de forma direta, nas atividades das escolas. Os professores também foram observados nas suas atuações cotidianas com as crianças e os adolescentes. As observações diárias foram realizadas nas três escolas onde a pesquisa foi aplicada, intercalando o turno matutino e vespertino para melhor observar as crianças e adolescentes participantes da pesquisa na sala de aula e nos demais espaços da escola como, por exemplo, sala de recurso multifuncional, salas de informática pedagógica, artes, educação física e refeitório.

Outros instrumentos utilizados para a aplicação da pesquisa foram o questionário com questões abertas, aplicado aos professores do ensino regular, o que possibilitou uma análise qualitativa do conteúdo encontrado ou dos dados coletados; o roteiro de questões para entrevistas semi-estruturadas, que foi aplicado aos pais e aos professores do ensino regular; o caderno de notas utilizado pelos professores 
regentes; e o diário de campo utilizado pelas pesquisadoras durante as observações in loco.

Quanto às respostas dos professores e às informações coletadas com as entrevistas aplicadas aos familiares, essas foram analisadas conforme referencial teórico de Bardin (2011), o qual indica que a análise de conteúdo consiste em um conjunto de técnicas de análise das comunicações percebidas. Portanto, nesse material, essas informações não foram vistas como utensílios de pesquisa, apenas, mas como um leque de apetrechos ou, com maior rigor, como aponta Bardin (2011), como instrumentos marcados por uma grande disparidade de formas e adaptáveis a um campo de aplicação muito vasto: as comunicações interpessoais e interinstitucionais.

Com base nas observações feitas durante a permanência das pesquisadoras em campo e considerando os depoimentos dos professores e familiares das crianças e adolescentes com deficiência e transtorno global do desenvolvimento, um conjunto de falas de professores e dos familiares foi reunido para análise.

Dessa análise, emergiram as categorias de análise da pesquisa, as quais se centraram nos termos mais enfatizados, mais repetidos e mais detalhadamente ilustrados pelos participantes, com base em três fases fundamentais: a pré-análise do material coletado, a exploração do material e a análise dos dados.

As categorias de análise da pesquisa do primeiro conjunto, que trata das expressões dos professores, são: Educação Inclusiva - Educação Especial: conceito e concepções; Formação de Professores; Relações: Pais, professores, Crianças e Adolescentes. O segundo conjunto trata das expressões das famílias: Concepção dos familiares sobre a inclusão escolar das crianças e adolescentes com deficiência e transtorno global do desenvolvimento; Encontros e desencontros na relação família-escola-atendimento educacional especializado; Importância do Atendimento Educacional Especializado - AEE e demais serviços para atender as necessidades específicas da criança ou adolescente com deficiência ou transtorno global do desenvolvimento para os familiares.

Neste artigo, foram consideradas apenas duas categorias: a concepção dos professores em relação à educação especial na perspectiva inclusiva e a concepção dos 
familiares sobre a inclusão escolar das crianças e adolescentes com deficiência e transtorno global do desenvolvimento. Dessas categorias, as pertencentes ao primeiro conjunto (concepção educação especial na perspectiva inclusiva) são decorrentes das expressões dos professores, e aquelas do segundo conjunto (concepção sobre inclusão escolar) são decorrentes das falas dos familiares.

\section{RESULTADOS E DISCUSSÕES}

Com o objetivo de organizar as discussões, inicia-se este item pela análise das falas dos professores, visando sempre perceber a concepção que esses têm em relação às crianças e adolescentes, público-alvo da educação especial no ensino regular, estudantes foco desta pesquisa. Em seguida, busca-se as falas dos familiares dos referidos estudantes.

Uma das professoras do ensino regular que atua no 1 o ano indica, de imediato, o pouco conhecimento que dispõe para trabalhar com alunos com deficiência ou transtorno global do conhecimento, e a necessidade que sente da presença de um segundo professor para auxiliá-la na tarefa da inclusão. Segundo essa professora $(P . R)^{3}$,

[...] O segundo professor é importante, não para fazer por ele, mas aí não distancia o aluno com deficiência do que está sendo visto com todos. Nós temos os outros, não são passivos, se fossem seria fácil. [...] Minha posição é de ter o segundo professor como no Estado.

Quando essa professora se refere ao segundo professor, seu desejo aponta para que este segundo professor se responsabilize pela criança com deficiência ou transtorno global de desenvolvimento. Percebe-se, pela expressão da professora, que a presença do estudante que apresenta essas características em sala de aula regular torna seu trabalho bem mais difícil.

\footnotetext{
${ }^{3}$ Neste artigo, ao nos referirmos à nominação dos entrevistados, estes aparecem: quando professores, o P. e a letra inicial do nome, exemplo: P.B.; quando familiares, o F. e o número de ordem de entrevista, exemplo: F.1.
} 
A Rede Municipal de Ensino de Joinville não conta com esse profissional, ao menos não com as características oferecidas nas escolas da Rede Estadual de Ensino de Santa Catarina. Ainda assim, de acordo com Portaria no 115 (JOINVILLE, 2008), a Rede Municipal oferece um auxiliar de educador monitor que atende as crianças e adolescentes com deficiência dependentes nas atividades da vida diária da escola, as quais envolvem alimentação, higiene pessoal e locomoção.

Outra professora da mesma unidade escolar (P.G) reforça essa concepção: "[...] Essa questão de inclusão é uma furada. [...] Enquanto não tiver ajuda, não adianta, a escola precisa se adaptar [...] para receber o aluno com deficiência, eu não tenho esse preparo".

Novamente, revela-se, nessa fala, certo temor por não estar preparada para atender esse tipo de estudante, e a professora culpa a falta de estrutura da escola para esse atendimento específico. Essa preparação poderia ser estimulada na própria escola, ao serem oportunizados ou ampliados momentos de troca de ideias sobre o tema "inclusão". Rodrigues (2006) provoca reflexões sobre o espaço da escola, indicando que é mais importante que ocorram mudanças de valores e atitudes enraizados em relação ao próprio conceito de deficiência do que se façam adaptações políticas ou pedagógicas. E Carvalho (1998, p. 193) aprofunda a discussão sobre a necessidade do estabelecimento de relações mais dialógicas:

A operacionalização da inclusão de qualquer estudante no espaço escolar deve resultar de relações dialógicas, envolvendo a família, escola e comunidade, de modo que cada escola ressignifique as diferenças individuais, bem como reexamine sua prática pedagógica.

Outro detalhe a ser destacado em relação à pesquisa é que os dados revelaram que, dentro de uma das unidades escolares, a professora que trabalha como auxiliar de educador monitor também sofre certa discriminação, e em geral é afastada das atividades desenvolvidas pelo conjunto de professores. Nessa escola, em particular, observou-se que os professores do ensino regular iriam participar de uma Reunião Pedagógica com a Direção para discutir aspectos pedagógicos importantes para a realização do processo educacional, e a auxiliar monitora (P.K.) não foi 
convidada a participar. Segundo a professora K., "[...] não participei, fiquei colaborando na decoração para o aniversário de 15 anos da escola e para o dia da família na escola que aconteceu no final de semana."

A professora do AEE também revela seu desencantamento com a profissão, afirmando que

[...] atualmente o que mais dificulta o meu trabalho é a falta de participação, o não diálogo e a falta de aplicação pedagógica por parte dos professores do ensino regular em relação aos recursos multifuncionais disponíveis para o trabalho com as crianças $e$ adolescentes atendidos pelo AEE. (P.J.)

Essa angústia é também compartilhada por outra professora do AEE de outra unidade escolar:

[...] consigo exercer minha função, mas poderia ter mais êxito se todos se comprometessem mais com a aprendizagem dos alunos com deficiência, pois o mesmo pertence à escola e não somente à auxiliar de educadora. E estar incluído é bem diferente de ser inserido. Os professores devem realizar avaliações partindo do que aquela criança já conhece dentro de suas capacidades. (P.G.)

Mantoan (2006) colabora com as reflexões, afirmando que, para que haja maior comprometimento de todos em torno da inclusão escolar, é necessário que a escola abra espaços para o diálogo, a solidariedade e o espírito crítico entre professores, administradores, funcionários e estudantes. Na escola, esta construção é possível, desde que haja, da parte de todos os envolvidos, um certo conhecimento sobre as diversas concepções de ensino e de aprendizagem e a compreensão de que é por meio de uma construção coletiva e pautada pelo respeito à diversidade que se desenvolve a educação verdadeiramente inclusiva.

Uma fala chamou a atenção das pesquisadoras. O professor M. afirmou: "sem segundo professor o aluno não aprende". Esta fala remete à reflexão sobre a questão da obrigatoriedade da inclusão de crianças e adolescentes nesta condição, proposta por Beyer (2005). O autor afirma que, quando o professor é obrigado a assumir a 
inclusão na qual não acredita, acaba criando estratégias que confirmem sua tese, atribuindo ao estudante com deficiência a responsabilidade pelo seu fracasso.

Outro dado significativo revelado pela pesquisa implica no fato de que oito professores apontaram que há falta de comprometimento das famílias no sentido de participação e de cobrança de seus direitos junto à escola e ao Estado. Essa "ausência" da família seria um fator que não contribui para a inclusão dos estudantes. Segundo uma das entrevistadas (P.B.),

percebe-se que a família ainda não tem total consciência da importância de participar e cobrar cidadania acessível. Muitos pais agem de maneira superprotetora, dificultando a autonomia e a independência que o filho deveria conquistar com condição para o desenvolvimento de suas capacidades.

Esta fala remete a reflexões sobre o reconhecimento dos pais quanto às reais capacidades para desenvolvimento da aprendizagem dos seus filhos e das alternativas de construção do conhecimento. A aceitação da deficiência a partir da família constitui-se um passo significativo para o avanço na superação das dificuldades. Para Paula (2007), cabe aos professores e demais profissionais da escola a tarefa de auxiliar e orientar os familiares nessa trajetória, porque, de início, os pais sentem-se inseguros diante da situação nova que estão vivendo: os filhos estão entrando na escola do ensino regular. Nesse sentido, sentem-se também despreparados em relação à deficiência, e isso pode gerar dificuldades nos primeiros contatos com os especialistas. Desde o início tudo é novo, os pais têm de aprender a lidar com uma situação desconhecida, que é a convivência diária com uma criança ou adolescente com deficiência em casa e com todas as recomendações dos professores que o atendem na escola. O importante seria uma relação mais próxima dos pais com os professores, ou seja, uma maior aproximação da família com a escola.

No entanto, essa proximidade nas relações entre professores e familiares não foi evidenciada pela pesquisa aqui relatada, conforme se destaca: 
Quase não tenho contato. (P.S.)

Não existe essa relação. (P.M.A.)

[...] o único contato que tenho é ver a mãe de um deles que sempre acompanha a saída e a entrada. Sou professora deles pelo quarto ano consecutivo e não fui eu quem não quis aproximação. (P.G.)

Em vista dessas informações, infere-se que não existe de parte das escolas o desejo manifesto de uma maior integração desses agentes educativos com os familiares dos seus alunos. Mittler (2003) indica que é necessário repensar a base das relações entre família e escola. Assim sendo, deve-se considerar que um bom relacionamento entre família e escola pode trazer melhoria na compreensão das necessidades, interesses e potencialidades das crianças e adolescentes e oportunizar o redesenho das suas trajetórias de ensino e de aprendizagem na escola. E em função disso, a escola poderia considerar novas situações e estratégias de socialização entre pais e professores.

Mas a pesquisa também apontou contradições. Apesar das críticas contrárias e negativas à relação pais-professores, treze dos professores entrevistados manifestaram estar satisfeitos com a participação das famílias no dia a dia das unidades escolares.

Quanto às falas dos familiares (F), observaram-se dois depoimentos que apontam na direção da construção de espaços educativos mais inclusivos. F5 assim expressou sua visão: "Sim, sim, no começo teve muita dificuldade, depois, daí com o tempo a gente vai se habituando com o meio [...]". E F6 reforçou esse pensamento, indicando que "na escola J. ela foi muito bem aceita, na sociedade eu vejo que as pessoas ainda têm preconceito, mas na escola do meu filho J. eu não tive problemas".

Na vida familiar, ou em sociedade, assim como na vida dentro da escola, os familiares passam por diversas fases cíclicas, incluindo, aí, o choque inicial da descoberta da deficiência da criança ou adolescente, a negação do diagnóstico e a busca por curas milagrosas, o luto e a depressão, até a entrada no estágio da aceitação e adaptação. As falas abaixo demonstram essa evolução na família.

Outro dado importante a ser destacado é que há pais que percebem a importância de que crianças e adolescentes nesta condição participem, convivam e se 
integrem à vida social. Segundo os depoimentos de dois familiares, a inserção na escola constitui-se em momento privilegiado para que os alunos aprendam a conviver em sociedade:

Ah! Eu acho que é muito importante, né, porque se a gente não colocasse na escola, na sociedade, quem iria criar? Como antigamente escondiam os filhos, e até na minha rua tem um rapaz, ele tá com dezesseis anos hoje, quase a idade de $R$, e ele nunca foi em nada, nunca frequentou nada. A gente olha assim, parece uma pessoa assustada, assim que ele vê a gente ele fica assustado. Eu acho que isso é muito importante. (F1)

[...] nessa escola, é tratado da mesma forma que as outras crianças. Eu vejo também por M. L. que é cadeirante, e eu vejo que elas conversam como se ela fosse uma criança normal. Isso pra mim já dá um pouco de base para saber onde meu filho tá. (F3)

Analisando os dados apresentados, percebe-se que esses revelam indicadores importantes para a presente discussão, em especial a falta de conhecimento de familiares e professores sobre a educação especial na perspectiva da educação inclusiva, no que se refere a: conceito; legislação; recursos; Atendimento Educacional Especializado e demais serviços; a resistência por parte de alguns professores quanto à presença de crianças e adolescentes com deficiência e transtorno global do desenvolvimento em sala de aula; a importância atribuída pelos professores em relação à inclusão da criança e do adolescente no ensino regular, desde que possam contar com todos os recursos necessários (humanos e de acessibilidade); e a manutenção de um adequado relacionamento dos familiares com as professoras do Atendimento Educacional Especializado e com os auxiliares de educadores monitores.

Com base no conjunto de depoimentos dos familiares, principalmente das mães, percebeu-se um misto de sentimentos iniciais frente ao diagnóstico de seus filhos: angústia; choque; medo; insegurança; tristeza; alegria; satisfação e susto; a visão positiva sobre a inclusão dos seus filhos nas unidades escolares; o desconhecimento do serviço do Atendimento Educacional Especializado e suas diretrizes e objetivos; a confusão das famílias sobre o Atendimento Educacional Especializado e o atendimento clínico; o entendimento de que o filho com deficiência, para que possa permanecer na escola, precisa de uma segunda professora que o 
acompanhe o tempo todo para atender as suas necessidades específicas; e, em alguns casos, considerar bom o contato que se mantém com os professores dos seus filhos.

\section{CONCLUSÕES}

O debate em torno da Educação Especial na Perspectiva da Educação Inclusiva mexe com as concepções, as posturas, as atitudes historicamente enraizadas e que insistem em permanecer no espaço escolar, dificultando e muitas vezes impedindo que as mudanças na instituição escolar ocorram.

As concepções por meio dos dizeres dos familiares e dos professores revelam a dificuldade que estes têm para compreender a inclusão escolar dos estudantes com deficiência e transtorno global do desenvolvimento, e reforçam o desconhecimento, as dúvidas e incertezas sobre os benefícios e as possibilidades da inclusão escolar, incertezas essas principalmente no que se refere à permanência e aprendizagem do estudante na escola por um período de quatro horas sem a presença de um auxiliar de educador monitor e/ou uma segunda professora. O estudo revelou, também, a importância da participação do estudante no Atendimento Educacional Especializado (AEE) no contra turno do ensino regular e, outro fator ainda, a importância do contato diário (ou não) dos profissionais da escola com a família.

De acordo com os dados coletados na pesquisa, o olhar sobre as unidades escolares deve ser um olhar de mudanças e inquietações, que venha mostrar a necessidade de transformações no sistema educacional no sentido de considerar as pessoas, suas histórias, concepções, percepções, crenças, experiências e trajetórias pessoais. Esses dados, portanto, trouxeram importantes contribuições para se pensar sobre as relações entre família, escola e Atendimento Educacional Especializado (AEE) no contexto da educação especial na perspectiva da educação inclusiva. Os dados apontaram diferentes questões que estão diretamente ligadas à temática do estudo e que contribuem para uma reflexão mais ampla sobre a inclusão escolar de estudantes com deficiência e transtorno global do desenvolvimento na escola regular. 
É importante destacar que a inclusão escolar de estudantes com deficiência não depende do grau de comprometimento ou do nível de desenvolvimento intelectual, mas, principalmente, depende da possibilidade de acesso, da interação e da adaptação do estudante ao grupo na escola. E esse se constitui o maior desafio para a escola hoje: reestruturar-se, modificar-se e aprender a conviver com diferentes gostos, interesses e níveis de desempenho. Enfim, conviver com a diversidade.

Observando pelo ponto de vista pedagógico, a inclusão escolar se torna essencial, pois oferece às crianças e aos adolescentes com necessidades específicas a possibilidade de interação com os demais alunos, ao mesmo tempo em que destaca a oportunidade de conviver e aprender junto com todos os outros alunos. Considerando-se esses aspectos, a realidade ainda está distante do desejado, já que a inclusão escolar é um processo em andamento.

O que se verifica é que, mesmo com toda a fundamentação teórica e legislação que garante a inclusão escolar das crianças e adolescentes que são público-alvo da educação especial na educação básica, e em detrimento de todos os esforços já empreendidos na construção de práticas inclusivas, ainda existem mecanismos de criação de subsistemas de educação especial no interior das escolas oferecendo, assim, espaços para sutis segregações de estudantes e de professores que atuam nessa área.

Assim, diante do exposto, entende-se que o processo inclusivo exige parceria. Faz-se necessário desenvolver um trabalho colaborativo entre os professores do ensino regular, as professoras do Atendimento Educacional Especializado e os auxiliares de educadores monitores, de modo que esses aprendam a compartilhar a responsabilidade pelo ensino de todos os estudantes, com ou sem deficiência e transtorno global do desenvolvimento.

Dessa forma, entende-se que a família e a escola constituem-se em instâncias primeiras para a inserção da criança na sociedade, ou seja, na vida pública. Sob esse viés, é de fundamental importância o estreitamento das relações para o desenvolvimento dessas crianças e adolescentes. Estudar numa rede de ensino regular possibilita aos estudantes com necessidades específicas acesso aos elementos que 
auxiliarão na construção de suas representações sobre o mundo, permitindo-lhes tornarem-se adultos autônomos e participativos. Tanto na família como na escola, as crianças e adolescentes podem experimentar o pertencimento e a diferenciação. Pertencimento por conviver com um grupo e se perceber semelhante, diferenciação por ser único, singular.

Sendo assim, faz-se necessário que os professores e os familiares tenham a convicção de que a escola precisa contar com o envolvimento de todos e com a busca constante por estudos científicos pertinentes a cada um dos casos de deficiência ou transtorno global de desenvolvimento para ampliar a compreensão sobre as crianças e os adolescentes, evitando, com esse movimento de aprendizagem, a estigmatização e a rotulação dos estudantes.

A pesquisa apontou que a inclusão escolar ainda é um desafio para os profissionais da educação. Indicou também que não é um conjunto de marcos legais que definem um projeto educacional, mas a forma como esses dispositivos são operacionalizados no contexto escolar.

Nesse encaminhamento, pode-se inferir que, como esta é uma pesquisa de abordagem qualitativa etnográfica, os dados obtidos e analisados não trazem conclusões definitivas, mas poderão servir de base para outras pesquisas, discussões, direcionamentos e olhares, com vista a uma melhor interpretação da relação educativa e afetiva entre família e escola. Espera-se que as considerações dessa pesquisa possam contribuir para a necessidade das políticas públicas voltadas para o desenvolvimento profissional dos professores da Educação Básica, fortalecendo, assim, o processo educacional inclusivo de todos os alunos nas redes regulares de ensino.

\section{REFERÊNCIAS}

ANDRÉ, M. E. D. A. de. Etnografia da Prática Escolar. 16. ed. Campinas, SP: Papirus, 2009.

ARANHA, M. S. F. Educação Inclusiva: A Fundamentação Filosófica. Ministério da Educação. Secretaria de Educação Especial. Brasília, DF: 2004. v. 1. 
BARDIN, L. Análise de Conteúdo. São Paulo: Edições 70, 2011.

BOCK, G. L. K. Deficiência e Diferença. Educação Inclusiva: Caderno Pedagógico. Florianópolis, 1a edição: Diretoria da Imprensa Oficial e Editora de Santa Catarina. Centro de Educação a Distância. Universidade Aberta do Brasil, 2012.

BRASIL. $\mathbf{O}$ acesso de alunos com deficiência às escolas e classes comuns da rede regular. Ministério Público Federal: Fundação Procuradora Pedro Jorge de Melo e Silva (org.). 2. ed. Brasília: Procuradoria Federal dos Direitos do Cidadão, 2004.

Política Nacional de Educação Especial na Perspectiva Inclusiva. Ministério da Educação. Secretaria de Educação Especial. Brasília, DF: 2008.

CARVALHO, R. E. Temas para Educação Especial. 2. ed. Rio de Janeiro: WVA, 1998.

CHUG, M. Representações de professores de uma escola pública sobre famílias de seus alunos. 1998. Dissertação de Mestrado. Universidade de Campinas, SP.

GOFFMAN, E. Estigma: notas sobre a manipulação da identidade deteriorada. 4. ed. Rio de Janeiro: RJ, 1988.

JOINVILLE. Portaria № 115. Secretaria Municipal de Educação. Gabinete do Secretário Municipal de Educação. Setembro, 2008.

MANTOAN, M. T. É. Inclusão escolar: O que é? Por quê? Como fazer? 2. ed. São Paulo: Moderna, 2006.

; SANTOS, M. T. T. dos. Atendimento Educacional Especializado: políticas públicas e gestão nos municípios. 1. ed. São Paulo: Moderna, 2010.

MAZZOTA, M. J. S. Educação Especial no Brasil: História e políticas públicas. 6. ed. São Paulo: Cortez, 2011. 
MINAYO, M. C. S.; DESLANDES, S. F.; GOMES, R. Pesquisa social: teoria, método e criatividade. 28. ed. Petrópolis, RJ: Vozes, 2009.

MITTLER, P. Educação Inclusiva: contextos sociais. Porto Alegre: Artmed, 2003.

MOSCOVICl, S. Representações Sociais: investigações em psicologia social. Petrópolis, RJ: Vozes, 2003.

NOGUEIRA, M. A. Relação família-escola: novo objeto na sociologia da educação. Paidéia, 8, 1998.

NUNES, D. G.; VILARINHO, L. R. G. Família possível na relação escola-comunidade. Psicologia Escolar e Educacional, 2001.

PAULA, A. R. DE. A hora e a vez da família em uma sociedade inclusiva. Brasília: Ministério da Educação, Secretaria de Educação Especial, 2007.

PEREZ, M. C. A; MARTINS, M. de F. A. Família-Escola: discutindo finalidades, rupturas e desafios no processo educativo. Brasília: MEC, 2007.

RODRIGUES, D. (Org.). Inclusão e exclusão: doze olhares sobre a educação inclusiva. São Paulo: Summus, 2006.

ROPOLI, E. A. et al. A Educação Especial na Perspectiva da Inclusão Escolar: a escola comum inclusiva. Ministério da Educação, Secretaria de Educação Especial. Fortaleza: Universidade Federal do Ceará, 2010.

SANTOS, M. T. C. T. dos. O Projeto Político Pedagógico, Autonomia e Gestão Democrática. In: ROPOLI, E. A. A Escola Comum Inclusiva. Ministério da Educação, Secretaria de Educação Especial. Fortaleza: Universidade Federal do Ceará, 2010.

SYMANSKI, H. A relação família-escola: desafios e perspectivas. Brasília: Líber Livro, 2010. 